Editorial

\title{
First anniversary of the journal anesthesia and critical care: open access (JACCOA)
}

Volume 2 Issue I - 2015

\section{Editorial}

A year ago, MedCrave an Open Access Publishing Group made available on the WEB the first issue of Anesthesia and Critical Care: Open Access (JACCOA), a journal that has been widely accepted in the international medical community. MedCrave decided to take the challenge to build a small group of specialists and professors from different countries interested in forming a select group of editors and associated editors with experience in anesthesiology and intensive care, to devote some of their valuable time and expertise to review the submitted articles and write their own experiences, thereby creating a medical journal available on the internet with clinical usefulness; not only as a forum for publication, but also as a reference journal with topics on these medical specialties.

The medical journals with open or free access have been growing rapidly around the world, predominantly those magazines written in English, since this language has been adopted as the language of science. This movement was generated in Europe, ${ }^{1-3}$ where some governments realized that traditional medical journals were too costly for most doctors, medicine and nurse students, and do not easy to distribute the knowledge and medical advances in most disciplines all over the world. Most of these advances are generated in public government hospitals and universities with their own patients, their researchers that generated most investigative protocols paid with financial resources of each country's GDP. Paid journals owned by large publishing companies print these new medical discoveries and advances, which are only available for members of some medical societies and paid subscribers. Only after some time - six or more months- some of these publishing companies opened their publications on the WEB, so colleagues around the world can download these important advances. The result of this costly system (money and resources paid by governments and published by editorial companies) was that the new research data arrived too late to the medical world and the benefit of improving the health care of millions of human beings was delayed considerably.

Open access and free access modality came to substantially modify the availability of this new knowledge with a positive result to improve the capability and competence of medical professionals regardless of their country, economic, racial, social or religious conditions, which ultimately result in a better care of persons suffering from illness, especially those human beings living in remote and poor areas. Another result, possible forced by the availability of many Open Access journals, was that some paid journals now have some free articles included in their latest issues, so recent information is available to all. Although open access mode has sparked much controversy, it has been shown that scientific publications in these journals have gained trust and reputation just like publications in paid journals, approaching similar scientific impact and quality as subscription journals. ${ }^{4}$

Anesthesia and Critical Care: Open Access was born as a journal with one goal: to spread scientific ideas and research information to

\author{
Victor MWhizar-Lugo \\ Department of Anesthesiology, Centro Médico del Noroeste, \\ México
}

Correspondence: Victor MWhizar-Lugo, Internal Medicine, Intensive Care,Anesthesiology, Centro Médico del Noroeste, Misión de San Diego 2993-306, Zona Urbana Rio Tijuana, Tijuana BC, México CP 22320, México, Tel +52-664-684-8905, Fax +52664-684-8906,Email vwhizar@anestesia-dolor.org

Received: January 19,2015 | Published: January 19, 2015

everyone. This project has come true due to the scientific contribution of colleagues who have honored us by sending their publications, and also to the readers that every day visits our website. In just 12 months six numbers have been published with a total of 38 articles; case reports 11, research protocols 10, Reviews 7, Editorials 5, Opinions 4, and Letter 1.

The scientific impact of these published articles has already begun to bear results and some of these publications have been cited in other scientific publications, a situation that will benefit our journal Impact Factor as in the possibility to index Anesthesia and Critical Care: Open Access, an important goal for MedCrave and the editors and coeditors.

As a member of the Editorial Board, I invite you to consider Anesthesia and Critical Care: Open Access as a journal for your forthcoming publications.

\section{Funding details}

None.

\section{Acknowledgments}

None.

\section{Conflicts of interest}

Authors declare that there is no conflicts of interest.

\section{References}

1. Abad-García MF, Melero R, Abadal E, et al. Autoarchivo de artículos médicos en repositorios de acceso abierto. Rev Neurol. 2010;50(7):431-440.

2. Berlin Declaration on open access to knowledge in the sciences and humanities (2003). Berlin.

3. Chatterjee P, Biswas T, Mishra V. Open access: the changing face of scientific publishing. J Family Med Prim Care. 2013;2(2):128-130.

4. Bjork BC, Solomon D. Open access versus subscription journals: a comparison of scientific impact. BMC Med. 2012;10: 73. 